\title{
Profits and competition under alternative technologies in a unionized duopoly with product differentiation ${ }^{\dagger}$
}

\author{
Luciano Fanti ${ }^{\mathrm{a}}$ and Nicola Meccheri ${ }^{\mathrm{a}, \mathrm{b},{ }^{, *}}$ \\ ${ }^{a}$ Department of Economics and Management, University of Pisa \\ Via C. Ridolfi, 10, I-56124 Pisa (PI), Italy \\ ${ }^{\mathrm{b}}$ RCEA, The Rimini Centre for Economic Analysis, Rimini, Italy
}

\begin{abstract}
:
This paper aims at investigating if the conventional wisdom (i.e. an increase of competition linked to a decrease in the degree of product differentiation always reduces firms' profits) can be reversed in a unionized duopoly model. We show that a decrease in the degree of product differentiation may affect wages, hence profits, differently, depending on both the firms' production technology and the mode of competition in the product market. Specifically, under constant returns to labour, the "reversal result" can apply under both Cournot and Bertrand competition, but it is more likely when firms compete in quantities. By contrast, under decreasing returns, profits can increase with competition but only if firms compete in prices.
\end{abstract}

Keywords: unionized duopoly, decreasing returns, product differentiation, profits JEL codes: J43, J50, L13

\footnotetext{
${ }^{\dagger}$ We are extremely grateful to an anonymous referee for comments and suggestions. Usual disclaimers apply.

*E-mails: 1fanti@ec.unipi.it (L. Fanti); meccheri@ec.unipi.it (N. Meccheri; corresponding author)
} 
A conventional wisdom in industrial economics suggests that a decrease in the degree of product differentiation always reduces firms' profits by increasing the intensity of product market competition, irrespective of the fact that firms compete à la Cournot or à la Bertrand (e.g. Shy 1995, pp. 138-140). The reason behind this result can be understood by referring to the standard differentiated duopoly model, due to Singh and Vives (1984), in which a decrease in the degree of product market differentiation diminishes total demand and induces firms to compete more aggressively under both modes of competition, leading unambiguously to lower profits.

While in the standard Singh and Vives's (1984) model firms' marginal costs are constant and exogenously given, the growing literature on unionized oligopolies (see, e.g., the seminal works by Horn and Wolinsky 1988 and Dowrick 1989) relaxes such assumption by admitting that (labour) costs are the outcome of a strategic game played between firms and unions before the former compete in the product market. In such a framework, recent works show that higher competition, measured in terms of the number of competing firms, can increase firms' profits. ${ }^{1}$ This paper also investigates the possibility of a "reversal result" (i.e. profits increase with competition) in a unionized duopoly model but, following Singh and Vives's (1984) spirit, focalizes on product differentiation/substitutability as the measure of the degree of competition in the product market.

Moreover, we introduce another important novelty into the analysis. Particularly, together with the standard case of labour constant returns technology considered by the previous literature, we also consider diminishing returns to labour, which imply increasing marginal costs. While the latter hypothesis is largely adopted in other strands of oligopoly theory (e.g. White 1996; De Fraja and Delbono 1990 in mixed oligopoly models, and Perry and Porter 1985; Heywood and McGinty 2007 in relation to the "merger paradox" in oligopolies), the effects that introducing a decreasing returns technology produces in a unionized oligopoly framework have so far not been investigated. ${ }^{2}$

Our main results can be summarized as follows. When wages are exogenously determined, the standard result that profits always decrease when competition increases remains valid irrespectively of the production technology by firms. However, when unions endogenously fix wages, more mixed results do emerge. In particular, when product differentiation decreases, together with the standard competition effect (that always operates in reducing profits), another

\footnotetext{
${ }^{1}$ References and a more detailed discussion are provided below.

${ }^{2}$ Exceptions are Fanti and Meccheri (2011, 2012a) that compare profits under alternative competition regimes (Cournot vs. Bertrand competition), and Fanti and Meccheri (forthcoming) that analyzes merger profitability under centralized unionization.
} 
effect, that we label endogenous or union wage effect, (indirectly) affects profits via changes in wages. We show that the patterns of behaviour of both the competition effect and the union wage effect differ according to the regimes of competition and technology, leading to mixed results in relation to the possibility that the standard (negative) relationship between competition and profits is reversed.

In particular, when labour displays constant returns, the conventional result can be actually reversed under both Cournot and Bertrand competition provided that unions sufficiently prefer wages to employment. Moreover, the range of product differentiation values, for which the reversal result applies, is larger when firms compete in quantities than in prices. Instead, under labour decreasing returns, the reversal result is generally more difficult to be obtained, since the competition effect is stronger under both competition regimes. However, we show that (provided that unions are sufficiently wage-oriented) the union wage effect can outweigh the competition effect but only if firms compete à la Bertrand. Hence, only under this mode of competition in the product market, the conventional wisdom can actually be reversed.

Various works deal with the relationship between competition and profits in a vertical structure. Naylor (2002a) shows the profits-per-firm raising effects of exogenous entry, which is linked to the fact that entry of a new firm has the effect of increasing the elasticity of the demand of labour, leading unions to bargain for lower wages. ${ }^{3}$ Similarly, in a model with cost difference between firms, Mukherjee et al. (2009) point out that entry in the market increases profits of the incumbent firms if the entrant firm is sufficiently cost inefficient as compared to the incumbents (see also Tyagi 1999 and Matsushima 2006).

Our work differs with respect to those above-mentioned in various aspects. Firstly, as already remarked, they measure competition by the number of firms competing in the product market. Instead, we refer to the degree of product differentiation. Although in both cases the possibility of the reversal result inevitably hinges on a negative relationship between competition and production costs (wages), the underlying mechanisms are different. This implies that final outcomes differ in relation to some important aspects. Most notably, while both Naylor (2002a) and Mukherjee et al. (2009) find that the positive relationship between competition and profits is more likely to occur if competition (i.e. the number of firms) is low, we obtain the opposite: when firms compete à la Cournot and labour exhibits constant returns, which is the framework considered by

\footnotetext{
${ }^{3}$ In Naylor (2002b) the same mechanism is considered to investigate the conditions under which industry profits as a whole are increasing with the number of firms in the market. However, as also recognized by Naylor (2002a, p. 2), "[i]t is less surprising that industry profits can increase with the number of firms as such a result is consistent with falling profits-per-firm".
} 
Naylor (2002a) and Mukherjee et al. (2009), the higher the degree of competition (i.e. the degree of product substitutability), the higher the possibility that the reversal result applies. Secondly, while previous literature considered constant returns to scale technology, we derive our outcomes under both labour constant and decreasing returns. This will permit us to compare the results under alternative technologies and, in particular, to highlight as technologies differently interact with diverse competition regimes. ${ }^{4}$

Given the key-role played by wages' behaviour in affecting our results, our work also deals with the literature studying the relationship between oligopoly competition in the final product market and unionized wages. The seminal article by Dowrick (1989) shows that higher competition reduces unionized wage. Considering a move from monopoly to duopoly, Bastos et al. (2010) provide open-shop unions and conclude that the theoretical negative relationship between competition and wages crucially hinges on the assumption that union density is one. More recently, however, Mukherjee (2012) generalizes Bastos et al. (2010) with multiple unionized and nonunionized firms, showing that if there are at least two firms initially (at least one of them is unionized), higher product market competition reduces unionized wage, irrespective of the union density. While such works consider linear production technology and competition in terms of number of firms, we generalize the negative relationship between wages and competition under decentralized unionization to the cases with diminishing returns to scale technology and competition in terms of the degree of product substitutability. Particularly, in our framework, such a negative relationship holds true irrespective of the technology, the competition regime in the product market and the union's preference for wage and employment. ${ }^{5}$

\footnotetext{
${ }^{4}$ Mukherjee et al. (2008) study the relationship between competition and profits under both Cournot and Bertrand competition. However, they maintain the standard hypothesis of constant returns to scale and concentrate on the case in which a monopolistic final goods producer can decide to license its technology to another firm (thus increasing competition means moving from monopoly to duopoly). Importantly, Mukherjee et al. (2008) also compare the cases with decentralized (firm-specific unions) and centralized (industry-wide) unionization. While here we concentrate on the firm-specific unions case, we refer to Fanti and Meccheri (2012b) for a study with centralized unionization and decreasing returns to labour.

${ }^{5}$ In Fanti and Meccheri (2012b), we show that if labour exhibits decreasing returns and unionization is centralized, the wage always increases with competition (measured in terms of the degree of product differentiation) when firms compete à la Cournot. On the other hand, under Bertrand competition, the relationship between the wage chosen by the central union and the degree of competition is "humped". Instead, in relation to the competition/profits nexus, the results of this paper (with decentralized unionization) qualitatively hold true even when unionization is centralized.
} 
Finally, it is worth remarking that there are reasons for which higher competition can increase firms' profits other than that operating via affecting wages. Recent studies show that market entry can soften competition, so that the market actually becomes less competitive as more firms enter. The reasons for such a result can be various; for instance, they can be linked to the strategic effect of entry on output or R\&D investment decisions by incumbent firms with different marginal costs (Pal and Sarkar 2001; Mukherjee and Zhao 2009; Ishida et al. 2011). We concentrate here on the role of product market differentiation in a duopoly model, while market entry is not taken into account. Moreover, the above-mentioned works do not tackle decreasing returns to scale, which instead are central in this paper.

The impact of the degree of product differentiation on equilibrium profits is considered by Zanchettin (2006), who modifies Singh and Vives's (1984) original framework by allowing for a wider range of cost and demand asymmetry between firms, finding that the efficient firm's profit and industry profits as a whole can decrease with the degree of product differentiation. By contrast, we relax the Singh and Vives's standard assumptions by introducing, instead of the presence of asymmetric firms, the role of unions and labour decreasing returns into the analysis. Hence, findings, as well as the economic mechanisms behind them, differ. Most notably, in our framework, when the conditions for the reversal result apply, both firms' profits increase with decreasing product differentiation, while in Zanchettin (2006) this only may occur for the most efficient firm.

The remaining part of the paper is organized as follows. Section 2 describes the basic framework and provides some preliminary analyses. Section 3 introduces the role played by unions in determining wages and analyzes how they behave under alternative technology and competition regimes. Results on the relationship between the degree of product differentiation (competition) and profits are presented and discussed in Section 4. Finally, Section 5 concludes while further details and technical proofs are provided in the Appendix.

\section{Economic environment and preliminary analysis}

We consider a model of differentiated product market duopoly where the product market inverse demand for the representative firm $i$ is linear and given by:

$$
p_{i}\left(q_{i}, q_{j}\right)=1-q_{i}-\gamma q_{j}
$$


with $q_{i}$ and $q_{j}$ denoting outputs by firm $i$ and $j(i, j=1,2, i \neq j)$, respectively, and $\gamma \in(0,1)$ the extent of product differentiation, with goods assumed to be imperfect substitutes. In particular, notice that if $\gamma$ would be equal to 1 , the products of the two firms would be undifferentiated, hence firms would compete in the same market. At the other extreme, if $\gamma$ would be equal to 0 , a monopoly would apply in this market. Hence, the higher $\gamma$, the higher the degree of competition in the product market. ${ }^{6}$

Let assume that only labour input is used for production. We consider the following production technology:

$$
q_{i}=l_{i}^{1 / \lambda}
$$

where $l_{i}$ represents the number of workers employed by the firm $i$ and $\lambda \in\{1,2\}$. Hence, in what follows we will consider two cases regarding production technology: labour constant returns (with $\lambda=1$ ) and labour decreasing returns (with $\lambda=2$ ). As already discussed in the Introduction, the case with constant returns, which also implies firms face constant marginal costs, is that considered by the previous literature. In this paper, we introduce also the case with labour decreasing returns in order to compare the results obtained under different technologies. This will permit to analyze the role of technology in affecting the profit/competition (degree of product differentiation) nexus in a unionized duopoly framework. Also note that the choice of the specific technology for the case with decreasing returns implies that firms have quadratic costs, which is a typical example of increasing costs in the literature. Furthermore, it allows for closed form solutions that, unfortunately, would not have been possible to be obtained with a more general value of $\lambda>1$.

The firm $i$ 's profit can be written as:

$$
\pi_{i}=p_{i} q_{i}-w_{i} l_{i}=p_{i} q_{i}-w_{i} q_{i}^{\lambda}
$$

where $w_{i}$ is the per-worker wage paid by firm $i$, with $w_{i}<1$.

For the (benchmark) case where the labour market is not unionized and wages are exogenous (i.e. $w_{i}=w_{j}=w$ ), it is possible to derive, according to the different modes of

\footnotetext{
${ }^{6}$ It is worth remarking that the (inverse) demand structure represented by (1), which is a normalized version of that originally introduced by Dixit (1979) and adopted by Singh and Vives (1984), not only implies that a lower degree of product differentiation (higher $\gamma$ ) increases competition but also reduces the total market size (e.g. Martin 2002, ch. 3.6).
} 
competition in the product market and different technologies, the following (symmetric) equilibrium values for firms' profit $\left(\pi_{i}=\pi_{j}=\pi\right):^{7}$

$$
\begin{array}{ll}
\pi_{1 C}=\frac{(1-w)^{2}}{(2+\gamma)^{2}} ; & \pi_{1 B}=\frac{(1-w)^{2}(1-\gamma)}{(2-\gamma)^{2}(1+\gamma)} \\
\pi_{2 C}=\frac{1+w}{[2(1+w)+\gamma]^{2}} ; & \pi_{2 B}=\frac{1+w-\gamma^{2}}{[2(1+w)+\gamma(1-\gamma)]^{2}}
\end{array}
$$

where the subscript $\lambda C$ recalls that they are obtained under " $\lambda$-technology" and Cournot competition in the product market, while the subscript $\lambda B$ means " $\lambda$-technology" and Bertrand competition.

Relative to the object of this paper, it is easy to check from (4) and (5) that, when wages are exogenously given, profit is positively correlated with the degree of product differentiation (which is decreasing in $\gamma$ ) or, in other words, is negatively correlated with the degree of market competition (which is increasing in $\gamma$ ). This holds true regardless the technology and the competition regime in the product market. Furthermore, from (4) and (5), we can also preliminarily infer that the negative (direct) effect of an increase of competition on profits is always stronger in the presence of labour decreasing returns implying, ceteris paribus, the reversal result is more difficult to be obtained under this technology. This is established by the following lemma.

Lemma 1. Under both Cournot and Bertrand competition, the (negative) "competition effect" is always stronger in the presence of labour decreasing returns.

Proof. See the final appendix (Section A.2).

\footnotetext{
${ }^{7}$ While the derivations of equilibrium profits under labour constant returns are standard, hence they are omitted for sake of space, those for the case with labour decreasing returns are provided in the final appendix (Section A.1).
} 

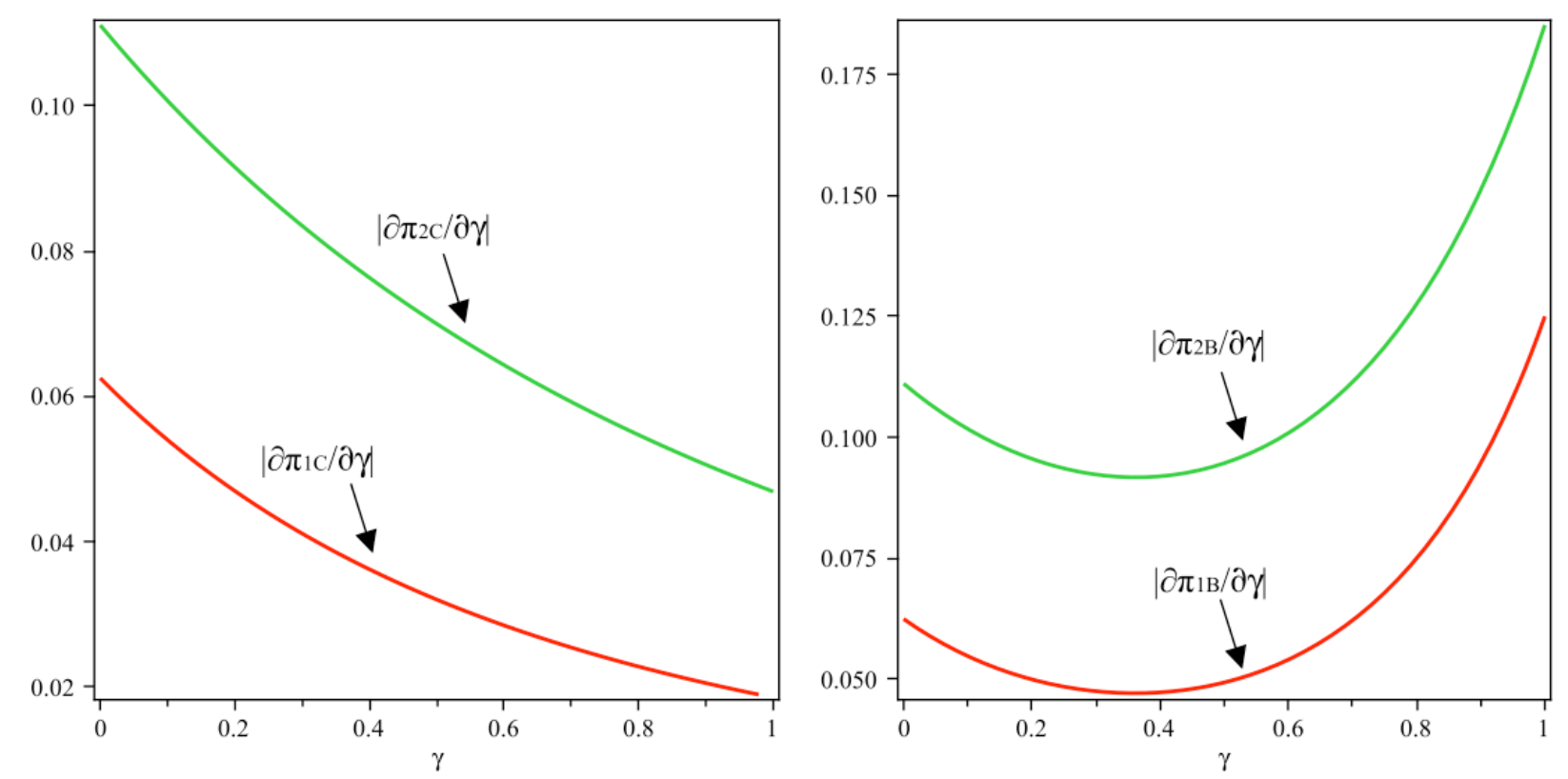

Figure 1: Competition effect under Cournot (left) and Bertrand (right) competition and alternative technologies $[w=0.5]$

While a formal proof of Lemma 1 is in the final appendix, Figure 1 provides a clear-cut illustration of the statement in the lemma. Furthermore, another important aspect (which will be investigated below in detail) arising from Figure 1 is the different behaviour displayed by the competition effect under alternative competition regimes, which suggests that, ceteris paribus, the reversal result is more difficult to be obtained for high values of $\gamma$ when firms compete in price.

\section{$3 \quad$ Unionized duopoly and wages under different production technologies}

In this section, we join the literature on unionized oligopolies (e.g. Horn and Wolinsky 1988; Dowrick 1989; Naylor 1998, 1999; Correa-López and Naylor 2004; Brekke 2004; Lommerud et al. 2005; Correa-López 2007) by admitting that labour cost is no longer exogenously given for firms, but it is the outcome of a strategic game played between each firm and a labour union. Firms' and unions' behaviour incorporates two stages of decision. Decisions are taken at each stage anticipating the outcome of subsequent stages. Following the backward induction logic, in stage 2, each firm decides, according to the production technology and competition regime, its optimal level of output, hence of factor inputs, given the input price (i.e. the wage) as determined at the prior stage. In stage 1, instead, firm-specific (monopoly) unions set wages.

As well known, union objectives are not necessarily dominated by wages. In particular, in order to derive tractable results for wage determination, we assume - following many other works 
(e.g. Pencavel 1985; Dowrick and Spencer 1994; Petrakis and Vlassis 2000) - that the union i's utility takes the following Stone-Geary functional form:

$$
V_{i}=w_{i}^{\theta} l_{i}=w_{i}^{\theta} q_{i}^{\lambda}
$$

where $\theta>0$ is a parameter that represents the degree of the union's orientation towards wages with respect to employment. ${ }^{8}$ In particular, a value of $\theta=1$ gives the total wage bill-maximizing case, while smaller $\theta$ 's values imply that the union is less concerned about wages and more concerned about employment. In what follows, we will derive equilibrium results according to alternative production technology (and competition regime).

\subsection{Labour constant returns $(\lambda=1)$}

Under labour constant returns, taking (1) and (3) (with $\lambda=1$ ) into account, profit-maximization under Cournot competition leads to the following firm $i$ 's best-reply function in the output space:

$$
q_{i}\left(q_{j}\right)=\frac{1-\gamma q_{j}-w_{i}}{2}
$$

From (7), and its equivalent for firm $j$, we can obtain the firm $i$ 's output for given $w_{i}$ and $w_{j}$ as:

$$
q_{i}\left(w_{i}, w_{j}\right)=\frac{2-\gamma-2 w_{i}+\gamma w_{j}}{4-\gamma^{2}}
$$

Similarly, when firms compete in prices, the firm $i$ 's best-reply function in the price space and the corresponding expression for the firm $i$ 's output for given $w_{i}$ and $w_{j}$ are, respectively:

$$
\begin{aligned}
& p_{i}\left(p_{j}\right)=\frac{1-\gamma\left(1-p_{j}\right)+w_{i}}{2} \\
& q_{i}\left(w_{i}, w_{j}\right)=\frac{2-\gamma(1+\gamma)-\left(2-\gamma^{2}\right) w_{i}+\gamma w_{j}}{\left(4-\gamma^{2}\right)\left(1-\gamma^{2}\right)}
\end{aligned}
$$

\footnotetext{
${ }^{8} \mathrm{~A}$ more general union's objective function is $V_{i}=\left(w_{i}-w^{\circ}\right)^{\theta} l_{i}$, which also includes the workers' reservation wage $w^{\circ}$. Since this will not affect qualitatively our results, for simplicity, we normalize $w^{\circ}$ to zero.
} 
Since both firms are unionized, unions' choices take place simultaneously across firms, taking the other firm's wage as given. Hence, by substituting (8), for the Cournot case, and (10), for the Bertrand case, in (6) (with $\lambda=1$ ) and maximizing with respect to $w_{i}$, we get the sub-game perfect best-reply function $w_{i}\left(w_{j}\right)$ under output and price competition as, respectively:

$$
\begin{aligned}
& w_{i}\left(w_{j}\right)=\frac{\theta\left(2-\gamma+\gamma w_{j}\right)}{2(1+\theta)} \\
& w_{i}\left(w_{j}\right)=\frac{\theta\left[2-\gamma(1+\gamma)-\gamma w_{j}\right]}{(1+\theta)\left(2-\gamma^{2}\right)} .
\end{aligned}
$$

From (11) and (12), symmetric sub-game equilibrium wages in different competitive contexts are given by, respectively:

$$
\begin{aligned}
& w_{1 C}=\frac{\theta(2-\gamma)}{2(1+\theta)-\theta \gamma} \\
& w_{1 B}=\frac{\theta[2-\gamma(1+\gamma)]}{(1+\theta)\left(2-\gamma^{2}\right)-\theta \gamma} .
\end{aligned}
$$

Result 1. When labour displays constant returns, under both Cournot and Bertrand competition, wages decrease when competition increases.

Proof. See the final Appendix (Section A.3).

Such findings make sense and, intuitively, can be explained by the fact that an increase of inter-firm competition in the product market, due to increased product substitutability, also translates into an increase of inter-union competition. More exactly, when $\gamma$ increases, employment at a firm level becomes more sensitive with respect to wages and this drives unions to undercut each other in wage setting in order to sufficiently preserve employment.

Furthermore, since the unions' preferences parameter $\theta$ will play a key role in the analysis that follows (particularly, in determining the reversal result relative to the nexus between competition and profits), it is worth also elucidating as $\theta$ affects, under different competition regimes, the reduction of wages due to increasing $\gamma$. 
Lemma 2. When labour displays constant returns, under both Cournot and Bertrand competition, there exists a "hump-shaped" relationship between the reduction of wages due to increasing competition and the parameter $\theta$, which reflects the degree of unions' orientation towards wages with respect to employment.

Proof. See the final Appendix (Section A.4).

The mechanism behind Lemma 2 can be explained by the fact that a change in wages takes place if modifying the degree of product differentiation affects the trade-off for unions between wages and employment. This actually occurs especially when both wages and employment matter for unions, that is, for medium values of $\theta .^{9}$ Instead, for small values of $\theta$, wages are low and there is not much room for wage reductions. Thus, as $\theta$ and the (equilibrium) wage increase, also the wage reduction due to increased product substitutability becomes more sizable. On the other side, for very high values of $\theta$, unions have a strong preference for high wages and, even though there is considerable room for wage reductions, a change in $\gamma$ will only trigger small wage adjustments.

\subsection{Labour decreasing returns $(\lambda=2)$}

In this section we introduce labour decreasing returns and the analysis parallels that of Section 3.1. Specifically, taking (1) and (3) (with $\lambda=2$ ) into account, profit-maximization leads to the following expressions for the firm $i$ 's output (for given $w_{i}$ and $w_{j}$ ) under Cournot and Bertrand competition, respectively:

$$
\begin{aligned}
& q_{i}\left(w_{i}, w_{j}\right)=\frac{2\left(1+w_{j}\right)-\gamma}{4\left(1+w_{i}\right)\left(1+w_{j}\right)-\gamma^{2}} \\
& q_{i}\left(w_{i}, w_{j}\right)=\frac{2\left(1+w_{j}\right)-\gamma(1+\gamma)}{4\left(1+w_{i}\right)\left(1+w_{j}\right)+\gamma^{2}\left[\gamma^{2}-2\left(w_{i}+w_{j}\right)-5\right]} .
\end{aligned}
$$

\footnotetext{
${ }^{9}$ The mechanism underlying such result is partly similar to that produced by a merger as discussed, e.g., in Lommerud et al. (2005).
} 
By substituting (15), for the Cournot case, and (16), for the Bertrand case, in (6) (with $\lambda=2$ ) and maximizing with respect to $w_{i}$, we get, according to the type of competition in the product market, the sub-game perfect best-reply function $w_{i}\left(w_{j}\right)$ as, respectively:

$$
\begin{aligned}
& w_{i}\left(w_{j}\right)=\frac{\theta\left[4\left(1+w_{j}\right)-\gamma^{2}\right]}{4(2-\theta)\left(1+w_{j}\right)} \\
& w_{i}\left(w_{j}\right)=\frac{\theta\left[4\left(1+w_{j}\right)+\gamma^{2}\left(\gamma^{2}-2 w_{j}-5\right)\right]}{2(2-\theta)\left[2\left(1+w_{j}\right)-\gamma^{2}\right]}
\end{aligned}
$$

which, in symmetric sub-game perfect equilibrium, lead to the following equilibrium wages in different competitive regimes:

$$
\begin{aligned}
& w_{2 C}=\frac{2(\theta-1)+\sqrt{\gamma^{2} \theta(\theta-2)+4}}{2(2-\theta)} \\
& w_{2 B}=\frac{\left(2-\gamma^{2}\right)(\theta-1)+\sqrt{\gamma^{2}\left[\gamma^{2}+\theta(\theta-2)-4\right]+4}}{2(2-\theta)} .
\end{aligned}
$$

Lemma 3. When labour displays decreasing returns, under both Cournot and Bertrand competition, an equilibrium with (strictly) positive wages does exist only if unions are not too much wage-oriented, that is, for $\theta<2$.

Lemma 3 defines a key-point, which will play a relevant role on the comparison between outcomes under alternative technologies. In particular, when labour displays decreasing returns, a reduction in output, due to increasing wages, affects employment more than proportionally. This means that, when unions are strongly employment-oriented, they fix low wages in order not to penalize employment excessively. However, as soon as unions are sufficiently wage-oriented, unions become very aggressive since, in order to recover the loss of utility from reduced employment, they strongly increase wages.

Specifically, from (19) and (20), it is easy to check that as $\theta$ increases, wages rise very quickly until they explode to infinity for $\theta \rightarrow 2$. However, when wages go to infinity, output and employment collapse to zero. This situation represents an example of the well-known "Cheshire Cat" union problem, in which setting higher wages would lead unions into extinction (e.g. Burda 
1990). For such a reason, for the case with labour decreasing returns, we will concentrate our analysis on $\theta \in(0,2)$.

The following result, instead, states as wages respond to changes in competition (degree of product differentiation) under decreasing returns, which parallels that above obtained with linear technology.

Result 2. When labour displays decreasing returns, under both Cournot and Bertrand competition, wages decreases when competition increases.

Proof. See the final appendix (Section A.5)

Finally, likewise what has been done for the case with constant returns, it is useful to analyze as $\theta$ affects, under different competition regimes, the relation between wages and competition.

Lemma 4. When labour displays decreasing returns, under both Cournot and Bertrand competition, the reduction of wages due to increasing $\gamma$ is always more sizeable as unions become more wage-oriented (i.e. as $\theta$ increases). However, only under Bertrand competition, such a reduction tends to be infinitely large as $\theta \rightarrow 2$.

Proof. See the final appendix (Section A.6).

When unions are not excessively wage-oriented $(\theta<2)$, the reduction of wages due to decreasing product differentiation increases with $\theta$ for reasons similar to those discussed in the presence of labour constant returns. However, it is important to point out that, when labour displays decreasing returns, there exists a crucial difference between what applies under Cournot and under Bertrand competition. ${ }^{10}$ Specifically, only when firms compete in prices, wage reductions always increase more than proportionally with respect to $\theta \in(0,2)$, tending to become infinitely large when the latter approaches its upper "critical level". Instead, under output competition, the behaviour of $|\partial w / \partial \gamma| / \partial \theta$ is " $\cap$-shaped". This difference will prove to be very important for the results that follow.

\footnotetext{
${ }^{10}$ This is in contrast with what asserted by Lemma 2, according to which, under constant returns to labour, the dynamics of $|\partial w / \partial \gamma| / \partial \theta$ maintains the same pattern of behaviour under both competition modes.
} 
Basing on previous analysis, in this section, we are able to answer to the following issue: do the standard results with exogenous wages described in Section 2, that increasing competition always decreases profits, holds true in the presence of unions in the labour market? And, which is the role of production technology (and competition regime) in addressing such an issue?

In order to deeply analyze the issue, consider first that when, e.g., the degree of product market differentiation decreases, hence product market competition increases, two distinct effects affect firms' profits. On the one hand, a direct effect (that we have above labelled as "competition effect") of increasing market competition for a given labour input price, which is always profitreducing. ${ }^{11}$ On the other hand, when wages are endogenously determined by unions, there is also an indirect effect (that we term "endogenous" or "union wage effect"), operating via changes in wages, which affects the pattern of behaviour between competition and profits. Formally, we get:

(21) $\frac{\partial \Pi}{\partial \gamma}=\underbrace{\frac{\partial \pi}{\partial \gamma}}_{\text {competition effect }}+\underbrace{\frac{\partial w}{\partial \gamma} \cdot \frac{\partial \pi}{\partial w}}_{\text {endogenous/union wage effect }}$

where, in general, $\Pi(\gamma, \theta)=\pi(\gamma, w(\gamma, \theta))$. In particular, when wages are exogenously given, the derivative of $w$ with respect to $\gamma$ is obviously zero, hence the endogenous wage effect is null. In such a case, only the competition effect operates and we get the standard result that, regardless of the mode of competition in the product market and production technology, profits always decrease with decreasing product differentiation. But when, instead, wages are fixed by unions, $\partial w / \partial \gamma$ is not actually null. Specifically, in such a case, as shown by Results 1 and 4, the endogenous wage effect is always positive, hence operates against the competition effect. Thus, the crucial issue is assessing which effect outweighs the other under alternative scenarios.

Result $3[\lambda=1$ and Cournot competition]. When labour displays constant returns and firms compete in output, provided that unions are more wage- than employment-oriented (that is, $\theta>1$ ), there is always some degree of product differentiation $\gamma$ sufficiently large, for which profits increase with competition. Moreover (provided that $\theta>1$ ), the higher $\theta$, the larger the range for $\gamma$ 's values, for which profits increase with competition.

\footnotetext{
${ }^{11}$ Furthermore, as shown above by Lemma 1, it is always stronger in the presence of labour decreasing returns.
} 
Proof. See the final appendix (Section A.7).

Result $4[\lambda=1$ and Bertrand competition]. When labour displays constant returns and firms compete in price, profits increase with competition, provided that unions are sufficiently wageoriented, that is $\theta>2.5$, and the degree of product differentiation $\gamma$ is neither too much small nor too much large. Moreover, (provided that $\theta>2.5$ ) the higher $\theta$, the larger the range for $\gamma$ 's values, for which profits increase with competition.

Proof. See the final appendix (Section A.8).

The content of Results 3 and 4 is graphically represented in Figure 2, where the parameter capturing the degree of unions' orientation towards wages is considered for a reasonable wide range (up to ten times with respect to employment). ${ }^{12}$

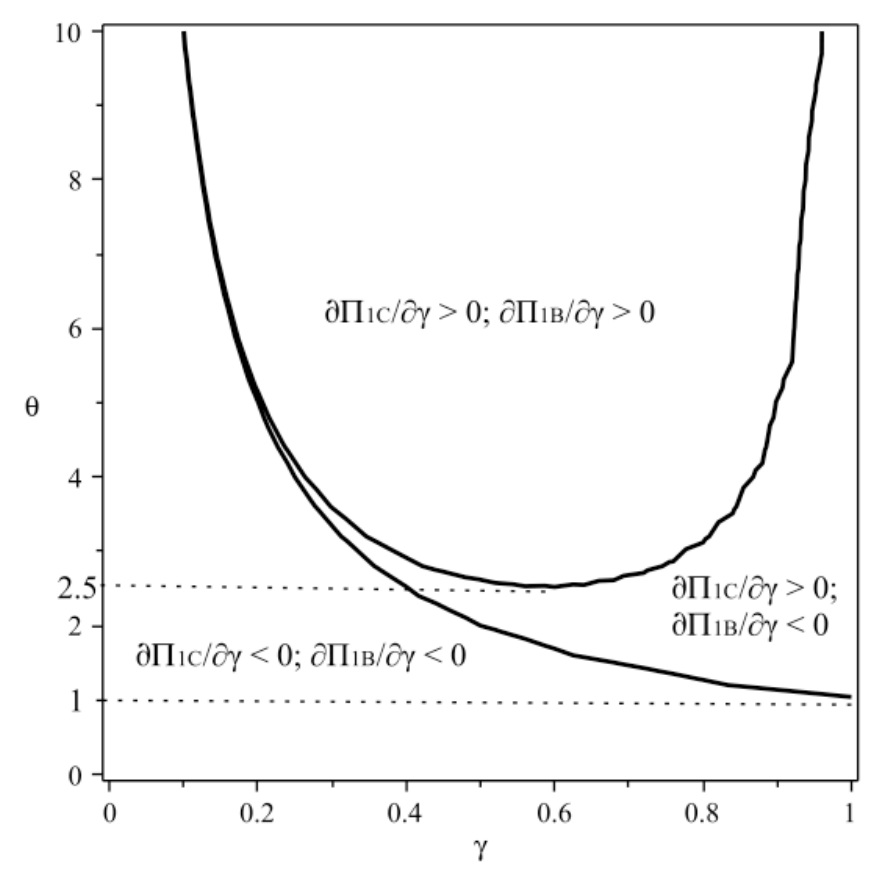

Figure 2: Profits' behaviour with respect to $\gamma$ under labour constant returns

\footnotetext{
${ }^{12}$ As shown in Appendixes A.7 and A.8, the "reversal result" never applies, under Cournot competition, when $\gamma \rightarrow 0$ and, under Bertrand competition, when both $\gamma \rightarrow 0$ and $\gamma \rightarrow 1$. This also implies that, for such a cases, $\theta$ (on the vertical axis of Figure 2) goes to infinity.
} 
From Results 3 and 4 (and from Figure 2), it arises that, when labour displays constant returns, the "reversal result" applies under both Cournot and Bertrand competition but it is more likely to occur when firms compete in output than in price. Specifically, it holds true that: a) there exist some $\theta$ 's values $(1<\theta<2.5)$, for which the reversal result applies, for some $\gamma$, only under Cournot competition; and b) when $\theta$ is sufficiently high $(\theta>2.5)$, such that the reversal result applies under both competition regimes, the reversal of the relationship between product differentiation and profits occurs for a larger range of $\gamma$ 's values under Cournot than under Bertrand. More exactly, the range of $\gamma$ 's values that meet the reversal result under Bertrand is always a subset of those that satisfy the reversal under Cournot competition.

This different pattern according to the competition regime can be largely related to the fact that, while the dynamics is quite similar under Cournot and Bertrand competition for relatively low values of $\gamma$, it undergoes a radical change when firms compete in price and products tend to become close substitutes. This is because, when price competition is extremely fierce and transfers to unions in the labour market, the unionized wage becomes extremely low. Indeed, from (13) and (14), it is possible to verify that, differently from $w_{1 C}, w_{1 B} \rightarrow 0$ when $\gamma \rightarrow 1$. Hence, as products become close substitutes, there is little room for wage reductions under price competition and the union wage effect tends to vanish. In turn, this implies that the conditions for the "reversal result" to apply become more and more difficult to be met.

Now, we turn to analyze the relationship between profits and competition under labour decreasing returns showing that, in such a case, results drastically differ with respect to those above discussed.

Result $5[\lambda=2$ and Cournot competition]. When labour displays decreasing returns and firms compete in output, firms' profits always decrease for increasing competition.

Proof. See the final appendix (Section A.9)

Hence, when firms compete $\grave{a}$ la Cournot in the product market and labour exhibits decreasing returns, the endogenous wage effect is never sufficiently strong with respect to the competition effect to overturn the standard result.

Result $6[\lambda=2$ and Bertrand competition]. When labour displays decreasing returns and firms compete in prices, provided that unions are sufficiently more wage- than employment-oriented, there exist a range for $\gamma \in(0,1)$ for which firms' profits increase with competition. 
Unfortunately, the nonlinearity of the expression for firms' profit under Bertrand competition and labour decreasing returns prevents us from using algebraic methods to derive a formal proof of Result 6. However, we can refer to numerical analysis, which is graphically illustrated by Figure 3 below, to provide a confirmation of such result. ${ }^{13}$

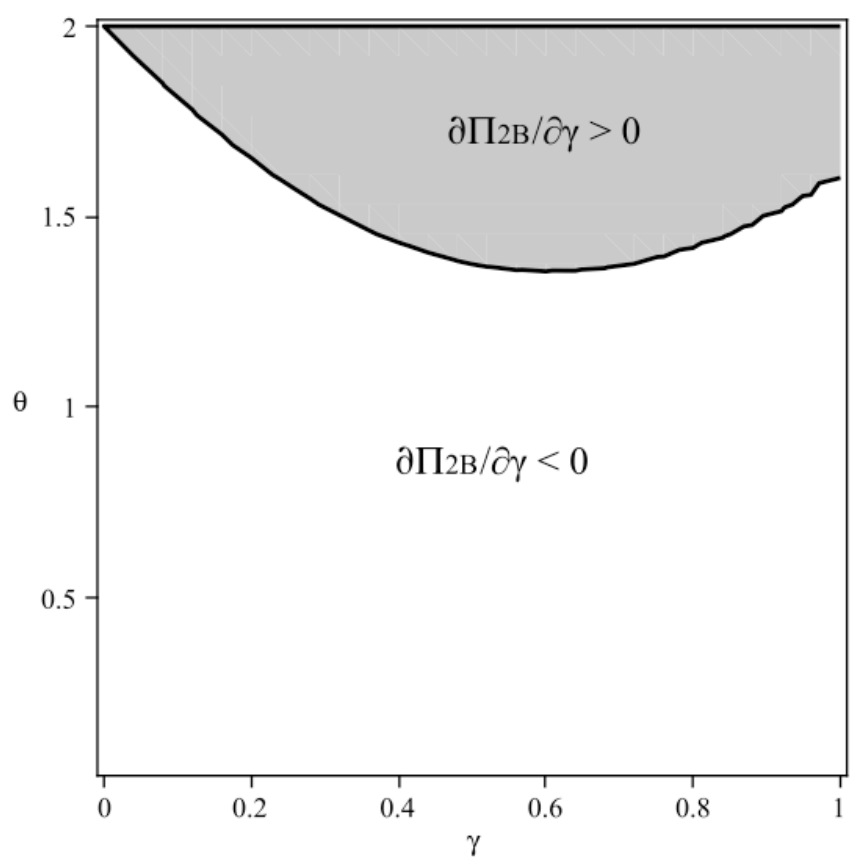

Figure 3: Profits' behaviour with respect to $\gamma$ under price competition and labour decreasing returns

In particular, in Figure 3 (which is represented for $\theta<2$, for which results are economically meaningful) the pairs belonging to the grey (white) area imply that profits increase (decrease) as the degree of product differentiation decreases (i.e. competition in the product market increases). Hence, from the figure, it clearly emerges that, if $\theta$ is sufficiently low, we get the conventional result that profits always decrease when competition increases. However, starting from a given threshold for $\theta$, the reversal result begins to apply and, as $\theta$ increases, the range for $\gamma$ for which profits increase with competition becomes larger and larger.

Finally, by comparing the results obtained under labour decreasing returns against those with linear production technology, we can note the following. In relation to Cournot competition, the reversal result only applies when labour displays constant returns. The reason can be related to the fact that the competition effect is stronger under labour decreasing returns (see Lemma 1). Thus, while under linear technology the wage effect is able to outweigh the competition effect for some

\footnotetext{
${ }^{13}$ All the numerical analyses and the graphical proof are derived in MAPLE (programs available from the authors upon request).
} 
values of $\gamma$ and $\theta,{ }^{14}$ this never applies under diminishing returns.

Instead, regarding price competition, although the competition effect remains stronger under decreasing returns, in this latter case the wage effect increases very rapidly as unions become more wage-oriented, tending to be infinitely large as $\theta \rightarrow 2$ (see Lemma 4). In turn, this striking pattern of behaviour exhibited by the wage effect implies that, when firms compete in prices and $\theta$ is sufficiently high, profits actually increase with competition also under labour diminishing returns. Moreover, when $\theta$ is lower (but not too much lower) than 2, the reversal result can realize only when labour displays decreasing returns (compare Figure 3 against Figure 2).

\section{$5 \quad$ Conclusion}

In this paper we have investigated the effects of the technology on the relation between (i) competition and wage, and (ii) competition and profits, in a unionized duopoly model with product differentiation. Relative to the first point, our results generalize those of the previous literature, which considered linear production technology and competition measured in terms of the number of firms, showing that higher competition always reduces unionized wage irrespective of the technology, the competition regime in the product market and the union's preference for wage and employment. As regards the second point, we have pointed out that, in our framework, mixed results arise. This is because, when product differentiation decreases and competition becomes fiercer, further than the standard competition effect (that always reduces profits), another effect, which indirectly operates via wages, affects profits. Furthermore, this indirect effect operates differently over wages (and profits), depending on the technology and the mode of competition in the product market. Specifically, under constant returns to labour, the "wage effect" can outweigh the standard "competition effect", hence a reversal of the conventional relationship between competition and profits can apply under both Cournot and Bertrand competition. However, this is more likely to occur when firms compete in quantities. By contrast, under decreasing returns to labour, profits can increase with competition but only if firms compete in prices. Therefore these outcomes highlight that - in addition to the other reasons discussed by the received literature technology also plays a crucial role in affecting the relationship between profitability and competition in a vertical structure.

\footnotetext{
${ }^{14}$ As shown in Figure 2, the value of $\theta$ should be sufficiently high in order to make the wage effect sizeable (see Lemma 2).
} 


\section{Appendix}

\section{A.1 Derivation of equilibrium profits under labour decreasing returns and exogenous wage}

Cournot competition. Taking (1) and (3) into account, profit-maximization under Cournot competition leads to the following firm $i$ 's best-reply function in the output space:

(A1) $\quad q_{i}\left(q_{j}\right)=\frac{1-\gamma q_{j}}{2\left(1+w_{i}\right)}$

From (A1), and its equivalent for firm $j$, we can obtain the firm $i$ 's output for given $w_{i}$ and $w_{j}$ as:

(A2) $\quad q_{i}\left(w_{i}, w_{j}\right)=\frac{2\left(1+w_{j}\right)-\gamma}{4\left(1+w_{i}\right)\left(1+w_{j}\right)-\gamma^{2}}$

and, by substituting in (3), the firm $i$ 's profit as:

(A3) $\pi_{i}\left(w_{i}, w_{j}\right)=\frac{\left(1+w_{i}\right)\left[2\left(1+w_{j}\right)-\gamma\right]^{2}}{\left[4\left(1+w_{i}\right)\left(1+w_{j}\right)-\gamma^{2}\right]^{2}}$.

With exogenous wages, we have $w_{i}=w_{j}=w$, hence, by substituting in (A3), we get an expression for equilibrium profit as defined, for the Cournot case, by (5) in the main text.

Bertrand competition. When competition is à la Bertrand, from (1) and its counterpart for the firm $j$, we can write product demand for the firm $i$ as:

(A4) $\quad q_{i}\left(p_{i}, p_{j}\right)=\frac{1-p_{i}-\gamma\left(1-p_{j}\right)}{1-\gamma^{2}}$

By substituting in (3) and differentiating, the first-order condition for profit-maximization gives the firm $i$ 's price choice, as a function of the price chosen by the firm $j$, as: 
(A5) $\quad p_{i}\left(p_{j}\right)=\frac{\left(1+2 w_{i}-\gamma^{2}\right)\left[1-\gamma\left(1-p_{j}\right)\right]}{2\left(1+w_{i}-\gamma^{2}\right)}$.

By substituting in (A5) the corresponding equation for the firm $j$ and solving for $p_{i}$, we get the Bertrand equilibrium price for given wages, $w_{i}$ and $w_{j}$ :

(A6) $\quad p_{i}\left(w_{i}, w_{j}\right)=\frac{\left(1+2 w_{i}-\gamma^{2}\right)\left[2\left(1+w_{j}\right)-\gamma(1+\gamma)\right]}{4\left(1+w_{i}\right)\left(1+w_{j}\right)+\gamma^{2}\left[\gamma^{2}-2\left(w_{i}+w_{j}\right)-5\right]}$.

Hence, by substituting in (A4), we get the sub-game perfect output as a function of wages as:

$$
q_{i}\left(w_{i}, w_{j}\right)=\frac{2\left(1+w_{j}\right)-\gamma(1+\gamma)}{4\left(1+w_{i}\right)\left(1+w_{j}\right)+\gamma^{2}\left[\gamma^{2}-2\left(w_{i}+w_{j}\right)-5\right]}
$$

and, by using (3), the firm $i$ 's profit as:

(A8) $\pi_{i}\left(w_{i}, w_{j}\right)=\frac{\left[2\left(1+w_{j}\right)-\gamma(1+\gamma)\right]^{2}\left(1+w_{i}-\gamma^{2}\right)}{\left[4\left(1+w_{i}\right)\left(1+w_{j}\right)-\gamma^{2}\left[2\left(w_{i}+w_{j}\right)+5-\gamma^{2}\right]\right]^{2}}$.

Again, with exogenous wages, we have $w_{i}=w_{j}=w$, hence, by substituting in (A8), we get an expression for equilibrium profit as defined, for the Bertrand case, by (5) in the main text.

\section{A.2 Proof of Lemma 1}

Proof. By differentiating (4) and (5) with respect to $\gamma$, we get:

(A9) $\frac{\partial \pi_{1 C}}{\partial \gamma}=-\frac{2(1-w)^{2}}{(2+\gamma)^{3}} ; \quad \frac{\partial \pi_{2 C}}{\partial \gamma}=-\frac{2(1+w)}{(2+2 w+\gamma)^{3}}$

(A10) $\frac{\partial \pi_{1 B}}{\partial \gamma}=-\frac{2(1-w)^{2}\left(1-\gamma+\gamma^{2}\right)}{(2-\gamma)^{3}(1+\gamma)^{2}} ; \quad \frac{\partial \pi_{2 B}}{\partial \gamma}=-\frac{2\left(1+w+\gamma^{3}\right)}{\left(2+2 w+\gamma-\gamma^{2}\right)^{3}}$.

By using equations in (A9) and (A10), we get: 


$$
\begin{aligned}
& \left|\frac{\partial \pi_{1 C}}{\partial \gamma}\right|-\left|\frac{\partial \pi_{2 C}}{\partial \gamma}\right|= \\
& -\frac{2 w\left[w\left(16+24 \gamma+6 \gamma^{2}-\gamma^{3}\right)+w^{2}\left(16-6 \gamma^{2}\right)-w^{3}(8+12 \gamma)-8 w^{4}+\gamma\left(12+12 \gamma+3 \gamma^{2}\right)\right]}{(2+\gamma)^{3}(2+2 w+\gamma)^{3}}<0, \forall w<1, \gamma \in(0,1) \\
& \left|\frac{\partial \pi_{1 B}}{\partial \gamma}\right|-\left|\frac{\partial \pi_{2 B}}{\partial \gamma}\right|= \\
& -\frac{2 w\left[\begin{array}{l}
w\left(16+8 \gamma-26 \gamma^{2}+29 \gamma^{3}+4 \gamma^{4}-25 \gamma^{5}+13 \gamma^{6}-4 \gamma^{7}+\gamma^{8}\right)+w^{2}\left(16-16 \gamma+10 \gamma^{2}+18 \gamma^{3}-24 \gamma^{4}+18 \gamma^{5}-6 \gamma^{6}\right) \\
-w^{3}\left(8+4 \gamma-16 \gamma^{2}+24 \gamma^{3}-12 \gamma^{4}\right)-w^{4}\left(8-8 \gamma+8 \gamma^{2}\right)+\gamma\left(12-12 \gamma-17 \gamma^{2}+20 \gamma^{3}-5 \gamma^{4}-8 \gamma^{5}+8 \gamma^{6}-2 \gamma^{7}\right)
\end{array}\right]}{(2-\gamma)^{3}(1+\gamma)^{2}\left(2+2 w+\gamma-\gamma^{2}\right)^{3}}<0,
\end{aligned}
$$

$\forall w<1, \gamma \in(0,1)$.

\section{A.3 Proof of Result 1}

Proof. Result 1 straightforwardly follows from differentiating (13) and (14) with respect to $\gamma$ :
(A11) $\frac{\partial w_{1 C}}{\partial \gamma}=-\frac{2 \theta}{(2+2 \theta-\theta \gamma)^{2}}<0, \forall \gamma \in(0,1)$
(A12) $\frac{\partial w_{1 B}}{\partial \gamma}=-\frac{\theta\left(2+\gamma^{2}\right)}{\left(2+2 \theta-\theta \gamma-\theta \gamma^{2}-\gamma^{2}\right)^{2}}<0, \quad \forall \gamma \in(0,1)$.

\section{A.4 Proof of Lemma 2}

Proof. By using (A11) and (A12), we get:

$$
\begin{aligned}
& \frac{\left|\partial w_{1 C} / \partial \gamma\right|}{\partial \theta}=\frac{2(2-2 \theta+\theta \gamma)}{(2+2 \theta-\theta \gamma)^{3}} \frac{<}{<} 0 \Leftrightarrow \theta \frac{<}{>2-\gamma} \\
& \frac{\left|\partial w_{1 B} / \partial \gamma\right|}{\partial \theta}=\frac{4-4 \theta+\theta \gamma^{4}+\theta \gamma^{3}+2 \theta \gamma-\gamma^{4}}{\left(2+2 \theta-\theta \gamma^{2}-\theta \gamma-\gamma^{2}\right)^{3}} \underset{<}{<} 0 \Leftrightarrow \theta \frac{2-\gamma^{2}}{>2-\gamma^{2}-\gamma} .
\end{aligned}
$$

\section{A.5 Proof of Result 2}

Proof. By differentiating (19) and (20) with respect to the degree of product differentiation $\gamma$, we get: 
(A13) $\frac{\partial w_{2 C}}{\partial \gamma}=-\frac{\gamma \theta}{2 \sqrt{\gamma^{2} \theta(\theta-2)+4}}<0, \forall \gamma \in(0,1)$ and $\theta \in(0,2)$

(A14) $\frac{\partial w_{2 B}}{\partial \gamma}=$

$\frac{\gamma\left[\theta(\theta-2)+2 \gamma^{2}-4+2(1-\theta) \sqrt{\gamma^{2}\left[\gamma^{2}+\theta(\theta-2)-4\right]+4}\right]}{2(2-\theta)\left[\theta(\theta-2)+2 \gamma^{2}-4+2(1-\theta) \sqrt{\gamma^{2}\left[\gamma^{2}+\theta(\theta-2)-4\right]+4}\right]}<0, \forall \gamma \in(0,1)$ and $\theta \in(0,2)$.

\section{A.6 Proof of Lemma 4}

Proof. By using (A13) and (A14), and defining $A \equiv 4+\theta^{2} \gamma^{2}-2 \theta \gamma^{2}+\gamma^{4}-4 \gamma^{2}$, we get:

$$
\frac{\left|\partial w_{2 C} / \partial \gamma\right|}{\partial \theta}=\frac{\gamma\left(4-\theta \gamma^{2}\right)}{2 \sqrt{\left(4-2 \theta \gamma^{2}+\theta^{2} \gamma^{2}\right)^{3}}}>0, \quad \forall \gamma \in(0,1) \text { and } \theta \in(0,2)
$$

$\frac{\left|\partial w_{2 B} / \partial \gamma\right|}{\partial \theta}=$

$\frac{\gamma\left[32+4 \theta^{2}-16 \theta+\theta^{3} \gamma^{2}-\theta^{2}\left(3 \gamma^{4}-8 \gamma^{2}\right)+\theta\left(6 \gamma^{4}-8 \gamma^{2}\right)-\gamma^{2}\left(32+2 \gamma^{4}-12 \gamma^{2}\right)+2 \sqrt{A^{3}}\right]}{2(\theta-2)^{2} \sqrt{A^{3}}}>0$,

$\forall \gamma \in(0,1)$ and $\theta \in(0,2)$.

\section{A.7 Proof of Result 3}

Proof. By using (4), (13) and (21), we get:

$$
\left.\frac{\partial \Pi_{1 C}}{\partial \gamma}\right|_{w=w_{1 C}}=\left.\frac{\partial \pi_{1 C}}{\partial \gamma}\right|_{w=w_{1 C}}+\left.\frac{\partial \pi_{1 C}}{\partial w}\right|_{w=w_{1 C}} \cdot \frac{\partial w_{1 C}}{\partial \gamma}=-\frac{16(1-\theta \gamma)}{(2+\gamma)^{3}(2+2 \theta-\theta \gamma)^{3}} \frac{>}{<} 0 \Leftrightarrow \theta=\bar{\theta}_{1 C} \frac{>1}{<\gamma}
$$

Firstly, notice that $\bar{\theta}_{1 C}$ is monotonically decreasing in $\gamma$. Secondly, when $\gamma \rightarrow 0, \bar{\theta}_{1 C} \rightarrow \infty$ and, when $\gamma \rightarrow 1, \bar{\theta}_{1 C} \rightarrow 1$. Both imply that: i) $\theta>\bar{\theta}_{1 C}$, hence profits increase with decreasing product differentiation for some $\gamma$, iff $\theta>1$; and ii) provided that $\theta>1$, the higher $\theta$, the larger the range for $\gamma \in(0,1)$ such that $\theta>\bar{\theta}_{1 C}$.

\section{A.8 Proof of Result 4}

Proof. By using (4), (14) and (21), we get: 
$\left.\frac{\partial \Pi_{1 B}}{\partial \gamma}\right|_{w=w_{1 B}}=\left.\frac{\partial \pi_{1 B}}{\partial \gamma}\right|_{w=w_{1 B}}+\left.\frac{\partial \pi_{1 B}}{\partial w}\right|_{w=w_{1 B}} \cdot \frac{\partial w_{1 B}}{\partial \gamma}=\frac{2 B}{(1+\gamma)^{2}(2-\gamma)^{3}\left(2+2 \theta-\theta \gamma-\theta \gamma^{2}-\gamma^{2}\right)^{3}} \frac{\geq 0 \Leftrightarrow}{<} 0 \Leftrightarrow \frac{\geq_{<}}{<}$

with

$B \equiv \theta\left(\gamma^{8}-\gamma^{7}-4 \gamma^{6}+4 \gamma^{5}+8 \gamma^{4}-8 \gamma^{3}-8 \gamma^{2}+8 \gamma\right)+\gamma^{8}-\gamma^{7}-5 \gamma^{6}+6 \gamma^{5}+6 \gamma^{4}-12 \gamma^{3}+4 \gamma^{2}+8 \gamma-8$.

It follows that:

$\left.\frac{\partial \prod_{1 B}}{\partial \gamma}\right|_{w=w_{1 B}} \underset{<}{<} 0 \Leftrightarrow \frac{\geq}{<} \bar{\theta}_{1 B}=\frac{8-\gamma^{8}+\gamma^{7}+5 \gamma^{6}-6 \gamma^{5}-6 \gamma^{4}+12 \gamma^{3}-4 \gamma^{2}-8 \gamma}{\gamma^{8}-\gamma^{7}-4 \gamma^{6}+4 \gamma^{5}+8 \gamma^{4}-8 \gamma^{3}-8 \gamma^{2}+8 \gamma}$

Firstly, notice that $\bar{\theta}_{1 B} \rightarrow \infty$ when both $\gamma \rightarrow 0$ and $\gamma \rightarrow 1$. Secondly, by differentiating, we get:

$\frac{d \bar{\theta}_{1 B}}{d \gamma}=-\frac{16+2 \gamma^{9}-7 \gamma^{8}+20 \gamma^{7}-10 \gamma^{6}-48 \gamma^{5}+48 \gamma^{4}+16 \gamma^{3}-8 \gamma^{2}-32 \gamma}{\gamma^{2}\left(\gamma^{5}-\gamma^{4}-2 \gamma^{3}+2 \gamma^{2}+4 \gamma-4\right)}$

which, on the interval $\gamma \in(0,1)$, has only one root in $\gamma \approx 0.59$. Moreover, we also have that $\left.\left(d^{2} \bar{\theta}_{1 B} / d \gamma^{2}\right)\right|_{\gamma \approx 0.59}>0$. Finally, by substituting for $\gamma \approx 0.59$ in $\bar{\theta}_{1 B}$, we get $\left.\bar{\theta}_{1 B}\right|_{\gamma \approx 0.59} \approx 2.5$. All that implies that, in $\gamma \in(0,1), \bar{\theta}_{1 B}$ is "U-shaped" with a minimum value of $\approx 2.5$, which, in turn, leads to Result 4 (see also Figure 2).

\section{A.9 Proof of Result 5}

Proof. By using differentiating (5), (19) and (21), and defining $C \equiv \sqrt{\gamma^{2} \theta(\theta-2)+4}$, we get:

$$
\begin{aligned}
\left.\frac{\partial \Pi_{2 C}}{\partial \gamma}\right|_{w=w_{2 C}}= & \left.\frac{\partial \pi_{2 C}}{\partial \gamma}\right|_{w=w_{2 C}}+\left.\frac{\partial \pi_{2 C}}{\partial w}\right|_{w=w_{2 C}} \cdot \frac{\partial w_{2 C}}{\partial \gamma}= \\
& -\frac{(2-\theta)^{2}[2(2+C)(2-\theta)(C+\gamma \theta)+\gamma \theta[2+(2-\theta) \gamma+C]]}{2 A[2+\gamma(2-\theta)+C]^{3}}<0, \forall \gamma \in(0,1) \text { and } \theta \in(0,2) .
\end{aligned}
$$




\section{References}

Brekke, K.R., 2004. Competition or coordination in hospital markets with unionised labour. International Journal of Health Care Finance and Economics 4, 65-89.

Bastos, P., Kreickemeier, U., Wright, P.W., 2010. Open-shop unions and product market competition. Canadian Journal of Economics 43, 640-662.

Burda, M.C., 1990. Membership, seniority and wage-setting in democratic labour unions. Economica 57, 455-466.

Correa-López, M., 2007. Price and quantity competition in a differentiated duopoly with upstream suppliers. Journal of Economics and Management Strategy 169, 469-505.

Correa-López, M., Naylor, R.A., 2004. The Cournot-Bertrand profit differential: a reversal result in a differentiated duopoly with wage bargaining. European Economic Review 48, 681-696.

De Fraja, G., Delbono, F., 1990. Game-theoretic models of mixed oligopoly. Journal of Economic Surveys 4, 1-17.

Dixit, A., 1979. A model of duopoly suggesting a theory of entry barriers. Bell Journal of Economics 10, 20-32.

Dowrick, S.J., 1989. Union-oligopoly bargaining. Economic Journal 99, 1123-1142.

Dowrick, S.J., Spencer, B.J., 1994. Union attitudes to labor-saving innovation: when are unions luddites. Journal of Labor Economics 12, 316-344.

Fanti, L., Meccheri, N., 2011. The Cournot-Bertrand profit differential in a differentiated duopoly with unions and labour decreasing returns. Economics Bulletin, 31, 233-244.

Fanti, L., Meccheri, N., 2012a. Labour decreasing returns, industry-wide union and CournotBertrand profit ranking. A note. Economics Bulletin 32, 894-904.

Fanti, L., Meccheri, N., 2012b. Profits and competition in a unionized duopoly model with product differentiation and labour decreasing returns. Discussion Papers 2012/133, Dipartimento di Scienze Economiche (DSE), University of Pisa. 
Fanti, L., Meccheri, N., forthcoming. Non-rigid wages and merger profitability reversal under convex costs and centralized unionization. Bulletin of Economic Research, published online.

Heywood, J.S., McGinty, M., 2007. Convex costs and the merger paradox revisited. Economic Inquiry $45,342-349$.

Horn, H., Wolinsky, A., 1988. Bilateral monopolies and incentives for merger. RAND Journal of Economics 19, 408-419.

Ishida, J., Matsumura, T., Matsushima, N., 2011. Market competition, R\&D and firm profits in asymmetric oligopoly. Journal of Industrial Economics 59, 484-505.

Lommerud, K.E., Straume, O.R., Sørgard, L., 2005. Downstream merger with upstream market power. European Economic Review 49, 717-743.

Martin, S., 2002. Advanced Industrial Economics, Second ed., Blackwell, Oxford, UK.

Matsushima, N., 2006. Industry profits and free entry in input markets. Economics Letters 93, 329336.

Mukherjee, A., 2012. Product market competition, open shop union and wage, Journal of Economics 107, 183-190.

Mukherjee, A., Zhao, L., 2009. Profit raising entry. Journal of Industrial Economics 57, 870.

Mukherjee, A., Broll, U., Mukherjee, S., 2008. Unionized labor market and licensing by a monopolist, Journal of Economics 93, 59-79.

Mukherjee, A., Broll U., Mukherjee, S. 2009. The welfare effects of entry: the role of the input market. Journal of Economics 98, 189-201.

Naylor, R.A., 1998. International trade and economic integration when labour markets are generally unionized. European Economic Review 42, 1251-1267.

Naylor, R.A., 1999. Union wage strategies and international trade. Economic Journal 109, 102-125.

Naylor, R.A, 2002a, The effects of entry in bilateral oligopoly, Warwick Economic Research Papers, University of Warwick. 
Naylor, R.A., 2002b. Industry profits and competition under bilateral oligopoly. Economics Letters 77, 169-175.

Pal, D., Sarkar, J., 2001. A Stackelberg oligopoly with nonidentical firms. Bulletin of Economic Research 53, 127-134.

Pencavel, J., 1985. Wages and employment under trade unionism: micro-economic models and macroeconomic applications. Scandinavian Journal of Economics 87, 197-225.

Perry, M., Porter, R.H., 1985. Oligopoly and incentive for horizontal merger. American Economic Review 75, 219-227.

Petrakis, E., Vlassis, M., 2000. Endogenous scope of bargaining in a union-oligopoly model: when will firms and unions bargain over employment? Labour Economics 7, 261-281.

Shy, O., 1995. Industrial Organization: Theory and Application. MIT Press, Cambridge (MA).

Singh, N., Vives, X., 1984. Price and quantity competition in a differentiated duopoly. RAND Journal of Economics 15, 546-554.

Tyagi, R.K., 1999. On the effects of downstream entry. Management Science 45, 59-73.

White, M.D., 1996. Mixed oligopoly, privatization and subsidization. Economics Letters 53, 189195.

Zanchettin, P., 2006. Differentiated duopoly with asymmetric costs. Journal of Economics and Management Strategy 15, 999-1015. 